\title{
Elasticidade-preço da demanda: uma análise do consumo da alface no município de Maceió no período de 2008 a 2013
}

\author{
Arcenor Gomes Neto* \\ André Maia Gomes Lages*** \\ Jonathan de França Santos****
}

\begin{abstract}
Resumo
Este trabalho tem como objetivo identificar as preferências do consumidor de Maceió, tendo como ponto de partida a análise da elasticidade-preço da demanda de alface no município no período de 2008 a 2013. Entender esse comportamento é de suma importância para a implementação de políticas que incentivem a produção de alface, pois grande parte da produção está em poder de pequenos agricultores, bem como tendo em vista a importância do seu consumo para a rotina de uma alimentação saudável. A partir de dados disponibilizados pela Ideral-Ceasa, foi possível realizar estimativas econométricas a fim de observar como os consumidores se comportam quando o preço da alface sofre aumento, o que pode ser investigado a partir do conceito de elasticidade-preço da demanda.
\end{abstract}

Palavras-chave: Elasticidade-preço da demanda. Comportamento do consumidor. Preferência por alface.

* Bacharel em Ciências Econômicas (UFCG). Mestre em Economia Aplicada (UFAL). E-mail: arcenoreconomista@gmail.com

** Doutor em Economia da Industria e da Tecnologia pela Universidade Federal do Rio de Janeiro (2003). Professor adjunto IV da Universidade Federal de Alagoas. E-mail: andre_lages@msn.com

**** Graduando em Ciências Econômicas pela Universidade Federal de Alagoas (UFAL). E-mail: jonathanfranca22@gmail.com

http://doi.org/10.5335/rtee.v24i51.9952

Submissão: 23/09/2019. Aceite: 18/10/2019. 


\section{Introdução}

O consumo de alface no Brasil merece destaque por ser a hortaliça mais consumida, influenciado pelo incentivo da Organização Mundial de Saúde (OMS) para o consumo de tais produtos, pois, assim, pode-se aumentar a prevenção de algumas doenças, além da importância do hábito da alimentação saudável. Como observado por Claro e Monteiro (2010), estima-se que 2,7 milhões de mortes por ano, segundo a OMS, estejam associadas ao consumo insuficiente desses alimentos.

No Brasil, o consumo da alface é em média de 1,2 kg/ano por brasileiro, dado que, embora seja a hortaliça folhosa mais consumida no país, ainda está abaixo do recomendado pela OMS.

A comercialização da produção agrícola é, conforme Coelho (2007), um dos maiores problemas enfrentados por pequenos e médios produtores, que representam a maior parcela da produção de alface no país. Analisar a forma pela qual ocorre a comercialização se faz necessário, visto que é nesse momento que a produção se transforma em mercadoria, como apontam Carvalho e Costa (2011).

É nesse processo que, a partir de um preço dado pelo mercado, se define a quantidade ofertada. A partir de então, acontece a decisão de compra por parte do consumidor: adquirir ou não tal produto. Os produtos agrícolas, nos quais se insere a alface, possuem uma característica peculiar, visto que sofrem oscilações de preço devido à sua vulnerabilidade às condições climáticas, as quais podem colocar a perder toda uma safra, assim como aos fatores de sazonalidade de safra.

Dessa forma, o problema da presente pesquisa é: qual o comportamento da elasticidade-preço da demanda por alface em Maceió no período de 2008 a 2013 ? Assim, tem-se como objetivo geral entender esse comportamento a partir de dados disponibilizados pela Central de Abastecimento de Alagoas no período que vai de janeiro de 2008 a dezembro de 2013. Os objetivos específicos são: i) sinalizar como os consumidores tomam as decisões de quais bens consumir; ii) investigar como se dá a comercialização de bens agrícolas no Brasil; e iii) mostrar, com base na elasticidade-preço da demanda, resultados empíricos que expliquem o comportamento do consumidor.

Para a obtenção de tal análise, será utilizada a regressão por mínimos quadrados ordinários (MQO), acompanhada pelos testes que aumentam a confiabilidade de tal modelo. Esse tipo de investigação é de suma importância, por se tratar de uma demanda de produtos agrícolas, visto que esses possuem características 
diferentes de outros bens, como de manufaturas e serviços, conforme explicam Unnevehr et al. (2010).

Para isso, o trabalho está estruturado da seguinte maneira: além desta breve introdução, faz-se uma análise geral do comportamento do consumidor, com apoio na literatura. Em seguida, procura-se entender como acontece a comercialização dos produtos agrícolas, pois é nessa fase que a produção estará à disposição dos consumidores como mercadorias. Após esse entendimento, será focado o mercado de hortaliças, em especial da alface, foco principal deste trabalho. Será ainda apresentada a metodologia utilizada, explicando a escolha do modelo simples por MQO, bem como a utilização dos testes. Destaca-se que será utilizado o modelo log-log. Com a obtenção dos resultados, faz-se a análise dos dados, seguindo, por fim, com as considerações finais.

\section{Entendendo a demanda do consumidor}

É de suma importância para o andamento da presente pesquisa entender o comportamento do consumidor, diante da vasta quantidade de bens ofertados pelo mercado. Faz-se uma análise geral de todos os tipos de bens e, em seguida, da demanda por alimentos, pois, como pode ser observado em Coelho (2007), o hábito de consumo alimentício está em constante mudança.

De acordo com Varian (1992), o objetivo de qualquer consumidor é o de encontrar no conjunto orçamentário a cesta de bens que esteja na curva de indiferença mais elevada, ou, em outras palavras, adquirir a cesta que lhe proporcione maior nível de satisfação de acordo com sua renda monetária, que é limitada.

Vale salientar, como já apontava Keynes (1964), que o consumo está em função da renda, princípio esse adotado na metodologia do estudo, pois, quanto maior a renda, consequentemente, o consumo tenderá a aumentar, de modo que os consumidores poderão adquirir bens que antes estavam impedidos por sua restrição orçamentária. Mas, passando dessa passagem macro para a microeconomia, o foco fica concentrado no resultado da elasticidade-preço da demanda.

Explicando tal processo de forma gráfica, tem-se a Figura 1: 
Figura 1 - Escolha dos consumidores

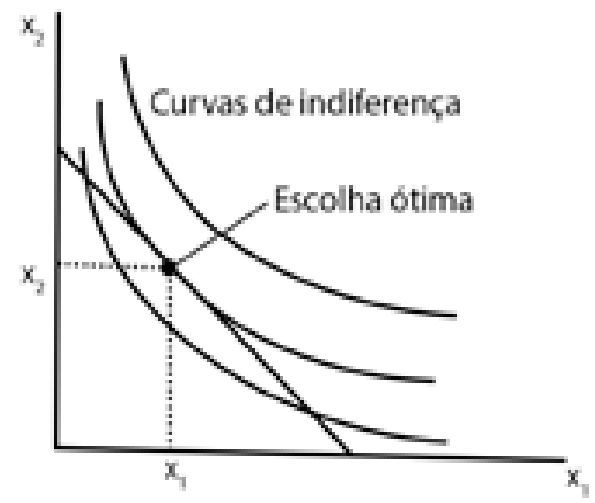

Fonte: Varian (1992, p. 78).

Na Figura 2, verifica-se uma curva preço-consumo que reflete uma possível diminuição de preço do bem 1, registrado no eixo horizontal. É a partir dos pontos de tangência entre a restrição orçamentária e as curvas de indiferença que podem ser extraídos os pontos da curva de demanda, quando a quantidade varia em função de variações do preço. No caso do gráfico apresentado na Figura 2, tem-se a variação da quantidade e do preço associado ao bem 1 . São mantidos constantes os preços do bem 2 e a renda monetária. Tal análise, de acordo com Varian (2009), considera, portanto, outras variáveis, como preço do bem 2 e renda constantes (ceteris paribus). 
Figura 2 - Curva de preço-consumo

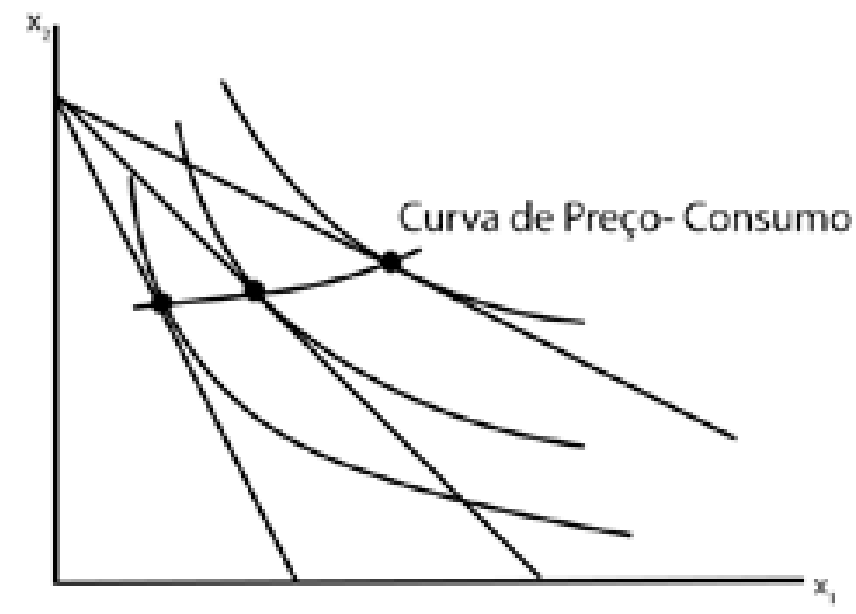

Fonte: disponível em: http://www.ie.ufrj.br/intranet/ie/userintranet/hpp/arquivos/08_-_aula_08_-_t_cons_-_escolha.pdf. Acesso em: 18 jul. 2019.

\section{Variações de preços: elasticidade-preço da demanda}

Os preços dos produtos são influenciadores da escolha do consumidor, assim, qualquer alteração acarretará mudanças na demanda, ainda mais na atualidade, visto a existência de uma enorme gama de bens, que podem ser considerados bens substitutos, o que a princípio levará o consumidor a escolher aquele bem com menores preços. A presença de muitos bens substitutos concorreria para uma demanda mais elástica.

Tal comportamento pode ser exposto pela elasticidade-preço da demanda, que nada mais é, de acordo com Santana et al. (2014), que o grau em que a quantidade demandada responde às variações de preços.

$$
E_{p}=\frac{\Delta Q}{\Delta P} \cdot \frac{P}{Q}
$$


Varian (2009) chama atenção para o sinal da elasticidade, o qual será sempre negativo, visto que uma das características da curva de demanda é a sua inclinação decrescente.

As conclusões da elasticidade-preço seguem alguns pressupostos, como destaca Varian (2009, p. 276):

If a good has an elasticity of demand greater than 1 in absolute value we say that it has an elastic demand. If the elasticity is less than 1 in absolute value we say that it has an inelastic demand. And if it has an elasticity of exactly 1, we say it has unit elastic demand.

Em outras palavras, $\mathrm{se}_{\mathrm{p}}>1$, a variação de $1 \%$ no preço, por exemplo, acarretará uma alteração maior que $1 \%$ na quantidade da demanda. Se $\mathrm{E}_{\mathrm{p}}<1$, a mesma alteração provocará uma mudança na demanda em menores proporções, ou seja, menor que $1 \%$. E, por fim, se $\mathrm{E}_{\mathrm{p}}=1$, a variação percentual do preço ocasionará uma alteração de mesma proporção da demanda. Todavia, importa lembrar que os valores são apresentados na forma modular, para não se restringir aos valores negativos.

Mendes e Padilha Junior (2007) chamam a atenção para alguns fatores que podem afetar a elasticidade-preço da demanda, determinando, assim, uma maior ou menor elasticidade entre os produtos. Dentre eles, destacam-se:

a) a existência de bens substitutos, visto que bens que possuam substitutos possuem maior elasticidade, pois, se o preço desse bem aumentar, o consumidor terá a alternativa de adquirir outro bem com as mesmas características, porém com um preço menor em relação ao bem inicial;

b) o número de utilizações do bem, pois, quanto maior o número de utilizações que podem ser empregadas ao bem, maior será a sua elasticidade-preço;

c) a proporção da renda empregada no bem, visto que produtos que necessitam de grande parcela da renda tendem a ser mais elásticos do que aqueles com pequeno peso no orçamento do consumidor;

d) o grau de importância do bem ou simplesmente bem necessário, este por natureza tende a ser inelástico a variações do preço, pois, mesmo que seu preço aumente, ele é de grande importância para o consumidor;

e) o período, devido a uma maior elasticidade no longo prazo ocasionada pelas maiores informações de bens substitutos que o consumidor tende a possuir com o passar do tempo. 
Os autores ainda chamam atenção para a existência do efeito novo consumidor, efeito renda e efeito substituição. O efeito novo consumidor acontece quando a redução do preço de um produto insere no mercado novos consumidores que antes estavam impedidos devido à sua renda. O efeito renda surge quando a queda no preço aumenta a renda real, dando maior poder de compra ao consumidor. E, por fim, tem-se o efeito substituição, em que a diminuição do preço de um produto aumenta a satisfação do consumidor, que pode adquirir maiores quantidades do bem frente ao seu substituto, que manteve o preço constante, por exemplo.

\section{Comercialização de produtos agrícolas}

O Brasil é um país de grande extensão territorial, o que causa uma produção agrícola com características heterogêneas, devido às particularidades de cada região. Uma análise simples está entre a Região Nordeste, conhecida por possuir uma parte da sua região com o clima seco, necessitando, assim, da especialização de produtos cultivados que sejam apropriados para essas condições. Também, tem-se a Região Sul, que possui regiões com fortes períodos chuvosos, de modo que se faz necessário o cultivo de produtos com essas propriedades. Assim, Coelho (2007) ressalta que a comercialização dos produtos é um dos maiores problemas enfrentados pelos pequenos e médios produtores.

Em se tratando da demanda de produtos agrícolas, considera-se de suma importância entender a sua comercialização, pois é um setor com impacto direto nos preços, influenciando a demanda do consumidor, que é o foco da presente pesquisa.

Como demonstram Carvalho e Costa (2011), a comercialização agrícola é a atividade mais complexa do sistema da agricultura, pois é nessa fase que a produção se transforma em mercadoria, sendo posta, assim, à disposição dos consumidores:

A comercialização agrícola envolve a transferência de bens, no caso a produção agrícola ou produtos semiprocessados aos consumidores. Em seu aspecto funcionalista, a comercialização agrícola perpassa a teoria e a prática de comércio, envolvendo “[...] todas as atividades, funções e instituições necessárias à transferência de bens e serviços dos locais de produção aos de consumo" (STEELE, 1971, p. 23). Além disso, a comercialização compreende atividades que resultam "[...] na transformação de bens, mediante utilização de recursos produtivos - capital e trabalho - que atuam sobre a matéria-prima agrícola” (BARROS, 2007, p. 01) (CARVALHO; COSTA, 2011, p. 95). 
Com a presença de tais características, conforme Rodrigues, Martins e Araújo (1997), os produtores necessitam se comportar como verdadeiros empresários, a partir de inovações, visto a forte exigência dos consumidores, que se deparam cada vez mais com uma enorme variedade de bens, e realizar periodicamente pesquisas de mercado, a fim de detectar variáveis que possam afetar a oferta de seus produtos e, consequentemente, os preços, que, por sua vez, interferem na demanda.

A alimentação - produção agrícola -, segundo Mendes e Padilha Junior (2007), é a primeira necessidade humana, seguida por vestuário, habitação, transporte, educação, cultura e lazer. Assim, a produção de alimentos é o segmento mais importante do agronegócio, que depende fundamentalmente das atitudes dos consumidores.

Assunção (2013) destaca a importância da Central de Abastecimento Atacadista para a comercialização dos produtos hortifrutigranjeiros tanto no atacado quanto no varejo, este em menor proporção. A maioria dos produtos repassados por essas centrais (Ceasa em Alagoas; Ceagesp em São Paulo) advém dos pequenos produtores, sendo, assim, um impulsionador da produção, pois, de certa forma, dá mais confiança aos produtores que contam com um canal de comercialização ajustado às necessidades de sua produção, dependendo do arranjo organizacional existente.

\section{A cultivação de hortaliças no Brasil}

O consumo de hortaliças é um aliado para uma vida saudável, como pode ser observado nos relatórios da OMS. ${ }^{1}$ Assim, Claro e Monteiro (2010) associam o baixo consumo desses alimentos ao risco elevado de doenças, visto que, de acordo com a OMS, 2,7 milhões de mortes por ano estejam associados ao seu consumo insuficiente.

Diante disso, a OMS estimula o consumo de hortaliças, sendo alvo de políticas adotadas por governos para tentar, de certa forma, incentivar a sociedade a aumentar o hábito de consumo saudável. Um exemplo de política é o Five a day fruits and vegetables for better health, que estimula a população norte-americana a consumir cinco porções diárias de frutas e hortaliças (COELHO, 2007).

Melo e Vilela (2007) apontam a existência de uma centena de espécies cultivadas, o que leva as hortaliças a constituir um grupo muito diversificado, com 
aproximadamente $60 \%$ da produção concentrada em propriedades familiares com menos de 10 hectares intensivamente utilizadas.

As hortaliças são classificadas de acordo com suas partes comerciáveis em três grupos distintos, sendo eles: hortaliças fruto, das quais utilizam-se os frutos ou partes deles, como o tomate, melancia e o quiabo; hortaliças herbáceas, cujas partes comestíveis localizam-se acima do solo, sendo tenras e suculentas, como as folhas (alface, repolho, taioba), talos e hastes (aspargo, aipo), flores e inflorescências (couve-flor, brócolis); hortaliças tuberosas, que englobam as raízes (cenoura, beterraba, batata-doce, rabanete), os tubérculos (batata, cará), os rizomas (inhame) e os bulbos (alho e cebola) (FIGUEIRA, 2000 apud COELHO, 2007, p. 20).

Economicamente, de acordo com Coelho (2007), a produção de hortaliças gera uma receita líquida superior quando comparada a qualquer outra cultura temporária, porém, necessita de meios de escoamento de produção, como é o caso da Ceasa, já citada anteriormente.

As hortaliças possuem características que auxiliam a sua produção durante todo o ano. Dentre essas características, Camargo Filho e Mazzei (1992) destacam seu curto prazo para colheita.

\section{A hortaliça mais consumida no Brasil: a cultura da alface}

O segmento das hortaliças possui uma grande quantidade de produtos, cada qual com suas próprias características. Conforme Coelho (2007), a alface pertence ao grupo das hortaliças herbáceas, grupo do qual a parte comestível são aquelas encontradas acima do solo, como folhas, talos, hastes, flores e inflorescências.

A alface é uma das primeiras hortaliças consumidas cultivadas pelo homem, como pode ser observado no estudo de Santos et al. (2008), originada no Mediterrâneo, sendo atualmente a hortaliça folhosa ou herbácea mais consumida no Brasil, como constatado por Assunção (2013). Trata-se de uma cultura de grande importância econômica e alimentar, visto que esse tipo de produto traz benefícios para uma alimentação saudável devido às suas características.

A importância da alface na alimentação e saúde humana se destaca por ser fonte de vitaminas e sais minerais, constituindo-se na mais popular dentre aquelas em que as folhas são consumidas. Seu consumo é feito in natura, e nessas condições apresenta a seguinte composição média, por 100 g: água: 94\%; valor calórico: $18 \mathrm{Kcal}$; proteína: 1,3 g; extrato etéreo: $0,3 \mathrm{~g}$; carboidratos totais: $3,5 \mathrm{~g}$; fibra: $0,7 \mathrm{~g}$; cálcio: $68 \mathrm{mg}$; fósforo: $27 \mathrm{mg}$; ferro: 1,4 mg; potássio: $264 \mathrm{mg}$; tiamina: $0,05 \mathrm{mg}$; riboflavina: $0,08 \mathrm{mg}$; niacina: $0,4 \mathrm{mg}$; vitamina C: 18,0 mg (OHSE et al., 2001, p. 181). 
Como acontece com a grande maioria dos produtos agrícolas, Rodrigues, Martins e Araújo (1997) chamam atenção para a sensibilidade da oferta da alface ocasionada pelas condições adversas de temperatura, fato também observado por Assunção (2013, p. 1-2):

As alfaces do tipo Crespa, Lisa e Americana apresentam indicações de que os preços de novembro a março sofrem variações para baixo influenciadas pelas quantidades ofertadas no mercado atacadista. Esse fato é provocado pelo fator clima, pois, nesse período é onde se concentra o maior volume de chuvas no Estado de Goiás, período no qual a produção de alface é diminuída. As plantas de alface não se desenvolvem completamente quando expostas a um rigor hídrico muito alto, apresentando doenças de origens fúngicas e bacterianas.

Com isso, pesquisas caminharam para a solução deste problema, focando no melhoramento genético e na produção em locais protegidos, possibilitando, assim, a sua produção em todos os períodos do ano, aumentando, consequentemente, a oferta no período chuvoso e impedindo grandes oscilações de preços. Costa et al. (2010) chamam a atenção para a produção do tipo hidropônico, um sistema de produção intensificado e bem aceito no mercado. Santos et al. (2008) também ressaltam o crescimento desse sistema de produção, o qual proporciona uma melhor utilização da área disponível para o cultivo, o baixo tempo necessário para a colheita - diminuindo os riscos inerentes à produção -, a utilização eficiente de nutrientes e uma produção de elevada qualidade.

Para Santos (2011), alguns fatores podem explicar o motivo pelo qual a alface seja a hortaliça mais consumida no Brasil, como a facilidade na sua aquisição, o seu sabor, a sua elevada qualidade nutritiva e o seu baixo custo. Ainda segundo o autor, em média, os brasileiros consomem $1,2 \mathrm{~kg} / \mathrm{ano}$, o que está abaixo do recomendado pela OMS, apesar, mais uma vez, de ser a hortaliça mais consumida.

\section{Metodologia}

O presente trabalho foi elaborado a partir de dados sobre a produção e o preço da alface no município de Maceió, AL, obtidos pela Central de Abastecimento (Ceasa) de Alagoas durante o período de janeiro de 2008 a outubro de $2013,{ }^{2}$ forneci-

dos diariamente pelo Instituto de Desenvolvimento Rural de Alagoas (Ideral), que serão utilizados para alcançar o objetivo da presente pesquisa, que é a análise de elasticidade-preço da demanda. 
A análise citada anteriormente foi calculada a partir de um modelo denominado de log-log, por Gujarati (2000), que permite verificar a relação da variação percentual de uma variável independente em outra dependente. Nesse caso, interessa justamente analisar o impacto da variação de preço da alface na sua quantidade de demanda.

Dessa forma, a utilização da estimação será por via da regressão por mínimos quadrados ordinários (MQO), como pode ser observado a seguir:

$$
\ln Q=a+\beta_{2} \ln P+u
$$

Sendo que:

$a=\ln \beta_{1}$;

$\beta_{2}=$ coeficiente de inclinação que mede a elasticidade de quantidade (Q) em relação ao preço $(\mathrm{P})$ ou, simplesmente, a elasticidade-preço da demanda;

$Q=$ quantidade de demanda de alface;

$P=$ preço da alface;

$u=$ termo do erro.

Ainda segundo Gujarati (2000), o modelo é conhecido como log-log justamente pela sua linearidade nos parâmetros $\alpha_{\mathrm{e}} \beta_{z}$ com os logaritmos das variáveis dependentes $(\mathrm{Q})$ e variável independente $(\mathrm{P})$.

Após a estimação da regressão por MQO, foram realizados o teste de Breush-Pagan e o teste White, para verificar a presença ou não de heterocedasticidade, em seguida foi realizado o teste de Durbin-Watson, com o intuito de verificar a presença de autocorrelação, dando, assim, maior robustez aos resultados obtidos com a regressão.

\section{Resultados e discussões}

Como supracitado, no caso dos produtos agrícolas, em especial da alface, objeto de estudo desta pesquisa, existe uma particularidade quando se analisa a demanda do consumidor, visto que são menos sensíveis às variações de preços, o que fica comprovado a seguir (Tabela 1). 
Tabela 1 - Resultados do modelo MQO

\begin{tabular}{l|r|r|r}
\hline \multicolumn{1}{c|}{ Variáveis } & \multicolumn{1}{c|}{ Coeficiente } & Desvio padrão & \multicolumn{1}{c}{$p>z$} \\
\hline $\operatorname{lnQ}$ & 1,324807 & 0,1138222 & 0,000 \\
\hline Constante & 6,750999 & 0,355645 & 0,000 \\
\hline No de observações & 69 & & \\
\cline { 1 - 1 } R-squared & 0,6691 & & \\
\cline { 1 - 2 } Adj R-squared & 0,6642 & & \\
\hline
\end{tabular}

Fonte: elaboração dos autores.

De acordo com a regressão apresentada, pode-se observar que o aumento de $1 \%$ no preço da alface - representado por $\ln \mathrm{P}$ - acarreta uma variação positiva da demanda - representado por $\ln Q$ - por alface em cerca de $1,32 \%$, ou seja, os consumidores continuam comprando alface mesmo que seja constatado um aumento nos preços. A variável explicativa $\ln P$ mostra-se estatisticamente significante ao nível de significância de 5\%, que pode ser constatado pelo valor t. Pode-se, ainda, afirmar que $66,91 \%$ das variações ocasionadas na demanda por alface se explica por alterações do preço, de acordo com o $\mathrm{R}^{2}$, e de acordo com o $\mathrm{R}^{2}$ ajustado, esse índice continua aceitável, sendo de $66,42 \%$.

A partir da hipótese de existência ou não de heterocedasticidade, foram realizados os testes de Breush-Pagan e White, para dar maiores poderes de explicação e de confiança ao modelo, como será apresentado na Tabela 2.

Tabela 2 - Teste de heterocedasticidade

\begin{tabular}{l|l}
\hline \multicolumn{1}{c|}{ Breush-Pagan } & \multicolumn{1}{c}{ White } \\
\hline chi2 $(1)=1,68$ & chi2 $(2)=5,87$ \\
\hline Prob $>$ chi2 $=0,1953$ & Prob $>$ chi2 $=0,0531$ \\
\hline
\end{tabular}

Fonte: elaboração dos autores.

De acordo com o teste de Breush-Pagan, é necessário considerarmos duas hipóteses.

$\mathrm{H}_{0}=$ Homocedasticidade

$\mathrm{H}_{1}=$ Heterocedasticidade 
Com os resultados obtidos pelo teste, não rejeitamos a hipótese nula, o que permite afirmar que não existe a presença de heterocedasticidade no modelo.

A fim de confirmar o resultado anterior, o teste White serve para detectar a presença de heterocedasticidade. Da mesma forma que o teste de Breush-Pagan, o teste White tem o mesmo resultado, o que permite afirmar de forma convicta que a regressão utilizada está livre da presença da heterocedasticidade.

Além desses testes, outros podem ser encontrados na bibliografia referente ao tema, para a averiguação de outros problemas que podem enfraquecer a análise aqui disponibilizada. Assim, a seguir será demonstrado o teste de Durbin-Watson (DW), que permite analisar se existe autocorrelação entre as variáveis (Tabela 3).

Tabela 3 - Teste de autocorrelação

\section{Durbin-Watson}

Durbin-Watson d-statistic $(2,69)=1,05055$

Fonte: elaboração dos autores.

De acordo com o resultado do teste DW, pode-se afirmar que não existe a presença de autocorreção. Assim, confirmando que o modelo está livre de tais problemas, pode-se afirmar que o modelo atende as suposições necessárias para ser considerado linear, dando confiabilidade aos resultados obtidos.

\section{Entendendo o resultado da elasticidade-preço da demanda da alface em Maceió}

Na regressão por $\mathrm{MQO}$ anteriormente realizada, pode ser observado que a demanda responde de forma positiva às variações de preço, mais precisamente a variação percentual de $1 \%$ nos preços, acarretando uma variação positiva na quantidade da demanda de aproximadamente $1,32 \%$.

Tal comportamento pode parecer entranho, visto que mesmo com um aumento dos preços os consumidores continuam a demandar alface. Faz sentido esse comportamento? A resposta viável para esse resultado pode ser observada nos fatores que podem influenciar no comportamento da elasticidade-preço da demanda, como já ressaltado no presente trabalho. 
Dentre os motivos que influenciam esse comportamento do consumidor, de acordo com Mendes e Padilha Junior (2007, p. 74), temos:

A proporção da renda gasta com o produto. A demanda de produtos que absorvem grande parcela da renda dos consumidores deve ser mais inelástica do que a de bens cujos dispêndios apresentam baixa percentagem da renda. A demanda por bens de preços elevados, que respondem por uma grande proporção da renda, será relativamente sensível ao preço, como é o caso de automóveis, casas, geladeiras, televisões, videocassetes, móveis, entre outros.

Então, esse fator demonstrado em Mendes e Padilha Junior (2007) esclarece o motivo pelo qual a demanda por alface em Maceió continua positiva mesmo com uma variação do preço para cima. Poderia ser considerado o caso do bem de Giffen, já que rompe com a lei da demanda, mas mereceria maior aprofundamento da análise, o que não é permitido pelas limitações das informações contidas nos dados.

Considere-se, então, que alface é um produto com baixo peso na cesta do consumidor, assim, uma variação positiva do preço terá baixo custo para o consumidor, que continuará a demandar tal produto, por motivos também já analisados anteriormente. Santos (2011) elege como responsáveis por tal comportamento a facilidade para sua aquisição, o sabor, a qualidade nutritiva e, sobretudo, o seu baixo custo. Deve ser lembrado ainda que a alface é sempre recomendada em dietas com orientação nutricional, então seu baixo peso no orçamento talvez justifique desconsiderar um aumento nos preços como forma de reduzir sua participação nas cestas de bens consumidos pelas famílias sinalizadas indiretamente naquela amostra. Contudo, os dados da Ceasa representam uma população estatística do que aconteceu naquele período referente ao comércio de alface naquela central atacadista.

\section{Considerações finais}

A presente pesquisa teve como principal objetivo analisar o comportamento da elasticidade-preço da demanda da alface no município de Maceió, considerando as limitações do modelo log-log por MQO para a obtenção dos resultados expostos.

Para entender a elasticidade-preço, se fez necessário relembrar alguns conceitos microeconômicos para o comportamento do consumidor, ator de suma importância para a continuidade deste trabalho. 
Varian (1992) destaca que qualquer consumidor tem como objetivo maximizar sua utilidade, o que pode ser obtido a partir da aquisição da melhor cesta de bens com a sua renda monetária, sendo esta a escolha ótima do consumidor.

Considerando que algumas variáveis podem sofrer alterações ao longo do tempo, Varian (2009) considera importante a análise da elasticidade-preço da demanda, que, segundo Santana et al. (2014), nada mais é do que o grau em que as quantidades de demanda sofrem alterações por variações nos preços.

Em se tratando da demanda por alimentos, a análise possui um fator peculiar, visto que esses produtos sofrem constantes oscilações de preços durante todo o ano, pois são vulneráveis às variações climáticas, assim como às variações consequentes de períodos de safra e entressafra.

O consumo de hortaliças vem crescendo no Brasil, embora ainda esteja abaixo do recomendado pela OMS, como observado por Claro e Monteiro (2010), que afirmam que o consumo desses produtos diminui a incidência de doenças, complementando, assim, um hábito de alimentação saudável.

Assim, a alface é a hortaliça folhosa mais consumida no Brasil, com grande parte da sua produção em poder de pequenos e médios produtores, devido à facilidade para o seu cultivo, processo que pode ser executado em pequenas áreas de terra de forma manual. Santos (2011) relata que os brasileiros consomem em média $1,2 \mathrm{~kg} /$ ano de alface, valor abaixo do recomendado pela OMS.

Após a análise dos resultados obtidos, pela estimação por MQO, pode-se perceber que a elasticidade-preço da demanda por alface é positiva ( $1,32 \%)$, o que significa que, embora os preços aumentem, a demanda por alface continua crescendo. Isso pode ser explicado também, conforme Mendes e Padilha Junior (2007), porque os produtos que possuem baixo peso na cesta dos consumidores sejam inelásticos às variações de preço, pois essas variações pouco influenciam na renda do consumidor. Por esse motivo é que a demanda por alface será mais apropriadamente um caso peculiar de um bem de Giffen. Os resultados foram além do que pode ser considerado como inelasticidade. 


\title{
Price elasticity of demand: an analysis of lettuce consumption in the municipality of Maceió from 2008 to 2013
}

\begin{abstract}
This work aims to identify the consumer preferences of Maceió, starting with the analysis of price elasticity of lettuce demand in the municipality from 2008 to 2013 . Understanding this behavior is extremely important for the implementation of policies that because most of the production is in the hands of small farmers, as well as the importance of their consumption for the routine of healthy eating. Based on data provided by Ideral-Ceasa, it was possible to make econometric estimates in order to observe how consumers behave when the price of lettuce increases, which can be investigated from the concept of price elasticity of demand.
\end{abstract}

Keywords: Price elasticity of demand. Consumer behavior. Lettuce preference.

\section{Elasticidad de precio de la demanda: un análisis del consumo de lechuga en la ciudad de Maceió de 2008 a 2013}

\author{
Resumen
}

Este trabajo tiene como objetivo identificar las preferencias de los consumidores en Maceió, teniendo como punto de partida el análisis de la elasticidad precio de la demanda de lechuga en el municipio de 2008 a 2013. Comprender este comportamiento es de suma importancia para la implementación de políticas que Fomentar la producción de lechuga, ya que gran parte de la producción está en manos de los pequeños agricultores, así como la importancia de su consumo para la rutina de una alimentación saludable. A partir de los datos proporcionados por Ideral-Ceasa, fue posible hacer estimaciones econométricas para observar cómo se comportan los consumidores cuando aumenta el precio de la lechuga, lo que puede investigarse desde el concepto de elasticidad precio de la demanda.

Palabras clave: Elasticidad precio de la demanda. Comportamiento del consumidor. Preferencia por la lechuga.

Classificação JEL: D11, Q11, Q13 


\section{Notas}

1 Disponível em: www.who.int/eportuguese/publications/pt/. Acesso em: 10 fev. 2018.

2 Destaca-se a ausência do mês de agosto de 2009 por falta de dados disponibilizados pela Ceasa.

\section{Referências}

ASSUNÇÃO, Paulo E. V. Relações de preços na comercialização de alface em Goiânia. Scientia Plena, Sergipe, v. 9, n. 7 (A), p. 22-36, 2013.

CAMARGO FILHO, Waldemar P. de; MAZZEI, Antonio R. Variação estacional de preços de hortaliças e perspectivas de mercado. Informações Econômicas, São Paulo, v. 22, n. 9, p. 33-56, set. 1992.

CARVALHO, Diana Mendonça; COSTA, José Eloízio da. Comercialização agrícola no Brasil. OKARA: Geografia em Debate, Paraíba, v. 5, n. 1, p. 93-106, 2011.

CLARO, R. M.; MONTEIRO, C. A. Renda familiar, preço de alimentos e aquisição domiciliar de frutas e hortaliças no Brasil. Revista Saúde Pública, São Paulo, v. 44, p. 1014-1020, 2010.

COELHO, Kenia de Souza. Perfil do consumidor de hortaliças frescas e processadas no município de Campos dos Goytacazes - RJ. 2007. 86 f. Dissertação (Mestrado em Economia) - Curso de Produção Vegetal, Centro de Ciências e Tecnologias Agropecuárias, Universidade Estadual do Norte Fluminense Darcy Ribeiro, Campos dos Goytacazes, 2007.

GUJARATI, D. N. Econometria básica. Tradução de Ernesto Yoshida. 3. ed. São Paulo: Pearson Mabron Boobs, 2000.

KEYNES, J. M. The general theory of employment, interes and Money. New York: Hancourt, Brace, Jovanovitch, 1964.

MELO, P. C. T.; VILELA, N. J. Importância da cadeia produtiva brasileira de hortaliças. Reunião Ordinária da Câmara Setorial da Cadeia 13. Produtiva de Hortaliças/ MAPA. Brasília, 2007.

MENDES, Judas Tadeu Grassi; PADILHA JUNIOR, João Batista. Agronegócio: uma abordagem econômica. São Paulo: Pearson Prentice Hall, 2007.

OHSE, Silvana et al. Qualidade de cultivares de alface produzidos em hidroponia. Scientia Agrícola, São Paulo, v. 58, n. 1, p. 181-185, 2001.

RODRIGUES, A. B.; MARTINS, M. I. E. G.; ARAÚJO, J. A. C. Avaliação econômica da produção de alface em estufa. Informações Econômicas, São Paulo, v. 27, n. 3, p. 27-35, mar. 1997.

SANTANA, Daline da Silva et al. Elasticidade-preço da demanda: uma análise comparativa entre Maçã Nacional e Laranja Lima no mercado alagoano. In: SOBER NE: NOVOS DESAFIOS PARA O DESENVOLVIMENTO, 1., 2014. Anais [...]. Caruaru, 2014. p. 1-18.

SANTOS, Ademir Oliveira et al. Produção de alface hidropônica: uma abordagem pela dinâmica de sistemas. In: CONGRESSO BRASILEIRO DE SISTENMAS, 4, 2008. Anais [...]. Franca, SP Uni-FACEF, 2008. 
SANTOS, Carlos Allan Pereira dos. Produção da alface crespa e umidade do solo em função de diferentes fontes de matéria orgânica e cobertura do solo. 2011. 59 f. Dissertação (Mestrado em Agronomia) - Curso de Agroecossistemas, Programa de Pós-Graduação em Agroecossistemas, Universidade Federal de Sergipe, São Cristóvão, Sergipe, 2011.

UNNEVEHR, Laurian et al. Food and Consumer Economics. 2010. Disponível em: https://academic.oup.com/ajae/article/92/2/506/88719. Acesso em: 19 abr. 2018.

VARIAN, H. R. Intermediate Microeconomics: a Modern Approach. 8. ed. New York: W.W. Norton \& Co, 2009.

VARIAN, H. R. Microeconomic Analysis. 3. ed. New York: WW Norton, 1992. 